\title{
WHO WORKS AT HOME?
}

\author{
Alison Loveridge \\ New Zealand Institute for Social Research and Development
}

The proportion of work which is casual, part-time, selfemployed or in some way insecure has increased during the 1980 s. Paid work carried out at home comes into many of these categories, and has been receiving attention because of the prevalence of low pay among home workers for the last 100 years. Asconsumer tastes change the actual work has changed, for example from making artificial flowers for hats to word processing. Allen and Wolkowitz (1987: 57) have argued that regardless of the task, working at home creates a situation where workers are vulnerable to exploitation. Contributing to this situation is the fact that they are isolated from other workers and may have taken this type of work because they have limited access to the job market.

\section{Conceptual Issues}

Definitions of home work often exclude self-employed people working at home (as opposed to contract workers who are disguised wage workers) because they are seen as having greater control over their situation. A British definition supplied in the Home workers (Protection) Bill 1979 is an example of such a definition:

an individual who contracts with a person not being a professional client of his for the purpose of that person's business, for the execution of any work (other than the production or creation of any literary, dramatic, artistic or musical work) to be done in domestic premises not under the control or management of the person with whom he [sic] contracts, and who does not normally make use of the services of more than two individuals in the carrying out of that work; (quoted in Allen and Wolkowitz 1987: 49).

Definitions of home work and attitudes to it vary. The argument that homework is underpaid and insecure is matched by one that praises the flexibility and autonomy available to home workers. These viewpoints focus on different categories of people working at home. When self-employed professionals with scarce skills work at home, because it reduces their business overheads or provides them with a flexible life-style, they may be able to earn a comfortable income. They may find their career prospects are more limited than those of their peers working in large firms, but feel compensated for this in other ways. At the other end of the spectrum are people who are not self-employed and are working at home because there is no other work available, whether or not they have commitments which prevent them from working full-time. The choice to use the position of the former to epitomise working at home may be bound up with a general support for a deregulated labour market which over-rides concern for the position of the worst off individuals. The lack of regulation of the conditions of home work, and the lack of statistics which could be used to monitor it, suggest, however, that this choice has been a factor in New Zealand. Farm work is another area where there has been less protection offered to workers than to the work force in general (Loveridge 1992: 35).

Because there is little information about employers of home workers it is very difficult to determine whether home work is a response to the needs of employers or of employees. Home work appears to be associated with minority groups with limited access to the labour market, new migrants, the disabled, those with dependents at home, older women, those with cultural disincentives to work outside the home etc. Some of these "minority groups", like women with young children, are very large. Allen and Wolkowitz (1987: 21) remind us that many members of these groups are able to access other types of work. A crucial issue in assessing home work is whether the job is defined as self-employment rather than wage work. Where workers are said to be on contract the link with those doing similar work on the employer's premises is broken and income and job security may be reduced. This is despite the lack of control these "contractors" have over their work flow and conditions. Home work is generally carried out on contract as direct supervision is not possible. This gives the employer considerable flexibility, as contract workers do not have to be paid for down-time, and there are no fixed costs to be paid when the work load is reduced, but home workers can be called upon when there is a busy period.

The literature on home work has increased over the last decade as feminist investigators have documented its history and the implications of its continued existence. The majority of home workers are women and there is concem that the problems associated with domestic labour: that it is unacknowledged, unrewarded and often done in conjunction with other activities which lead to a double working day, are more likely to influence the structural position of women doing paid home work than those in the 
general work force. Because home work is associated with exploitative working conditions there has been concern that it is so poorly documented in official statistics, and a desire to see conditions improved. Despite the problems associated with home work, it is a convenient option for some people whose situation limits their access to the general labour market (Boris and Daniels 1989: 28). Making it illegal would deny these people their right to work or make their labour market position even more vulnerable.

Recent studies include: investigation of the type of work which is carried out, the conditions under which it is done, the type of people who are involved, what it means to them, and where home work fits into an analysis of relations of production. Like self-employment in small businesses, home work has superficial resemblances to pre-capitalist forms of production, but having been continually subjected to the demands of capitalist production since industrialisation it cannot be seen as an anachronism; it meets the contemporary needs of large employers for flexibility and cost reduction. Current trends towards the fragmentation of the work force and the reduction in the welfare responsibilities administered by the state may foreshadow as increase in home work.

Field work addressing these issues has been done overseas but New Zealand has focused on the clothing industry (eg Foggo 1992). Conditions may be different elsewhere, although it is likely that there will be similarities. One reason is the dearth of suitable secondary data on home workers and another is the methodological problems of tracing people who work at home. This paper is intended to provide an introduction to the New Zealand situation but will only be able to address some of these central issues speculatively. When DSIR Social Science ordered the data set on which this paper is based the Unit was interested in the relationship between a particular sort of technological change, the introduction of computers and information technology, and working at home. Staff members were not primarily interested in the nature of home work and further work in this area has not been funded. As a consequence this paper is descriptive and will not be able to enter into theoretical debates on the nature of wage work within capitalism. Issues such as the motivations of employers and employees cannot be addressed, and those such as the role of gender or the degree of autonomy home workers really have are difficult to address with the type of information provided by the New Zealand Census of Occupation and Dwellings. Those interested in them should turn to other sources, for example Armstrong (forthcoming). Further analysis of the census data is possible for those with specific questions. In addition inferences from the following analysis can be followed up by contact with individuals and organisations ${ }^{1}$.

\section{Methodological Issues}

Many of the studies made of home work in New Zealand and elsewhere have looked at jobs from the manufacturing sector which have been "put out" to women working at home (Allen and Wolkowitz 1987:53). This work includes sewing, assembling and making small objects, packaging, cooking etc. Clerical and secretarial tasks are also common. However many other types of work are carried out at home, often by people who are self-employed. Many shopkeepers and people running cafeterias or accommodation live on the premises. A range of professional people from music teachers, to engineers, to ministers of religion work at home. There is no distinction made between people who work at home in the New Zealand census data, and people who are based at home but work on their clients' premises.

The data available to us is based on the census question "How did you travel to work?" This means that those who are based at home and travel to clients elsewhere are not separated from those who work in the home itself ${ }^{2}$. Farm people have been excluded from the comparisons mide between the home and full work force in this study hecause of definitional problems. Although only about half of the people working on farms listed themselves as workıng at home in the census, they make up two-thirds of those statod to be working at home and their presence would bias the figures. The number of non-farm people working at home in 1986 was 47,682 , while the number of non-farm people in the full labour force was 1,323,204 - the following tables are based on these figures.

The same tasks may be done for an employer on wages, on contract or as a self-employed business owner. Some workers such as sales or trades people use their homes as a base for their business but carry out most of the work elsewhere. Although people based at home are often selfemployed, there is an overlap for these categories and census data would have to be examined job by job to make the distinction, with no security that all the people in any one job were home based or home workers anyway. Because census data makes it difficult to separate these different types of occupation in any work which aggregates data to look at general issues, such as gender or income and employment status, it is difficult to carry out any research which is theoretically driven by an interest in relationships between employers and employees.

As I mentioned above, my initial interest in home work was linked to technological change, and this aspect has been discussed more fully elsewhere (Loveridge and Schoeffel 1991). It will also be followed up in forthcoming work with 1991 census data which will trace change in the range of jobs carried out by home workers between 1986 and 1991. The impact of technological change should show up in specific occupations such as computer programming and data entry, and implications about potential use can be drawn and can be usefully pursued using census data. Within this focus on technological change self-employed people are as interesting as wage workers, and the separation of home based work and home work is less of a problem for us than for other researchers. Separating the data relating to individual occupations requires much less time than re-aggregating data according 
tonew categories and this paper uses the categories provided by the census because the budget for this project did not allow re-aggregation of the data.

Some characteristics are known to be indicators of market situation: gender, employment status, education, and income. This paper uses income for full or part-time work by occupational major group to measure whether home work appears to represent opportunity or lack of opportunity in New Zealand. Information on other variables such as family budget and dependents was not collected and we would be interested in sharing data with others whose focus on home work is different to ours.

Contract workers cannot be separated from the selfemployed or employees. Census data provides categories which do not make this distinction: self-employed with or without workers, wage or salary earners or unpaid workers. We have combined these into self-employed and other workers, excluding the unemployed, who could move into the work force in either capacity. Education is available in numerous categories but has been broken down into tertiary versus non-tertiary as this distinction provides a clear indication of differences within identical occupations. Age is less controversial and I will not comment on it in any detail in this paper ${ }^{3}$. Despite methodological problems the aggregate census data provides an indication of the variation which exists within the work force in general. The insights from tracing individual occupations help us to interpret the aggregate figures.

\section{Occupation}

In New Zealand a relatively large proportion of the nonfarm work force declares itself as working at home (approx $3 \%$ ). White collar jobs are more prevalent among home workers than the general work force. Those working at home are more likely to be in clerical ( $23 \%$ compared with $20 \%$ ) and service (17\% compared with $11 \%$ ) work, with relatively fewer people in production, construction and transport ( $35 \%$ compared with $23 \%$ ), while proportions of sales people, managers and professional people are almost identical (see Figure One ${ }^{4}$ ). This is not surprising, given that many jobs in production and transport require either large scale machinery housed in factories, or continuous movement from site to site. Those from these fields that do work at home are spread across a wide variety of occupations, but few are in food processing or heavy industry. A variety of home and home based jobs were carried out (see Table One). The figures show some of the more common jobs, and also demonstrate the differences by gender and employment status. Problems with census definitions, eg waged working proprietors also show up.

Most home workers are full-time (61\%), although not as many as in the general work force (85\%). Part-time work is defined as 30 hours or more a week. Women home workers are fairly evenly divided etween full and part-time work (29\% and $33 \%$ ), but men are concentrated in fulltime work, only $5 \%$ are part-time. The literature on home

\section{Figure 1. Homeworkers- occupation by sex}

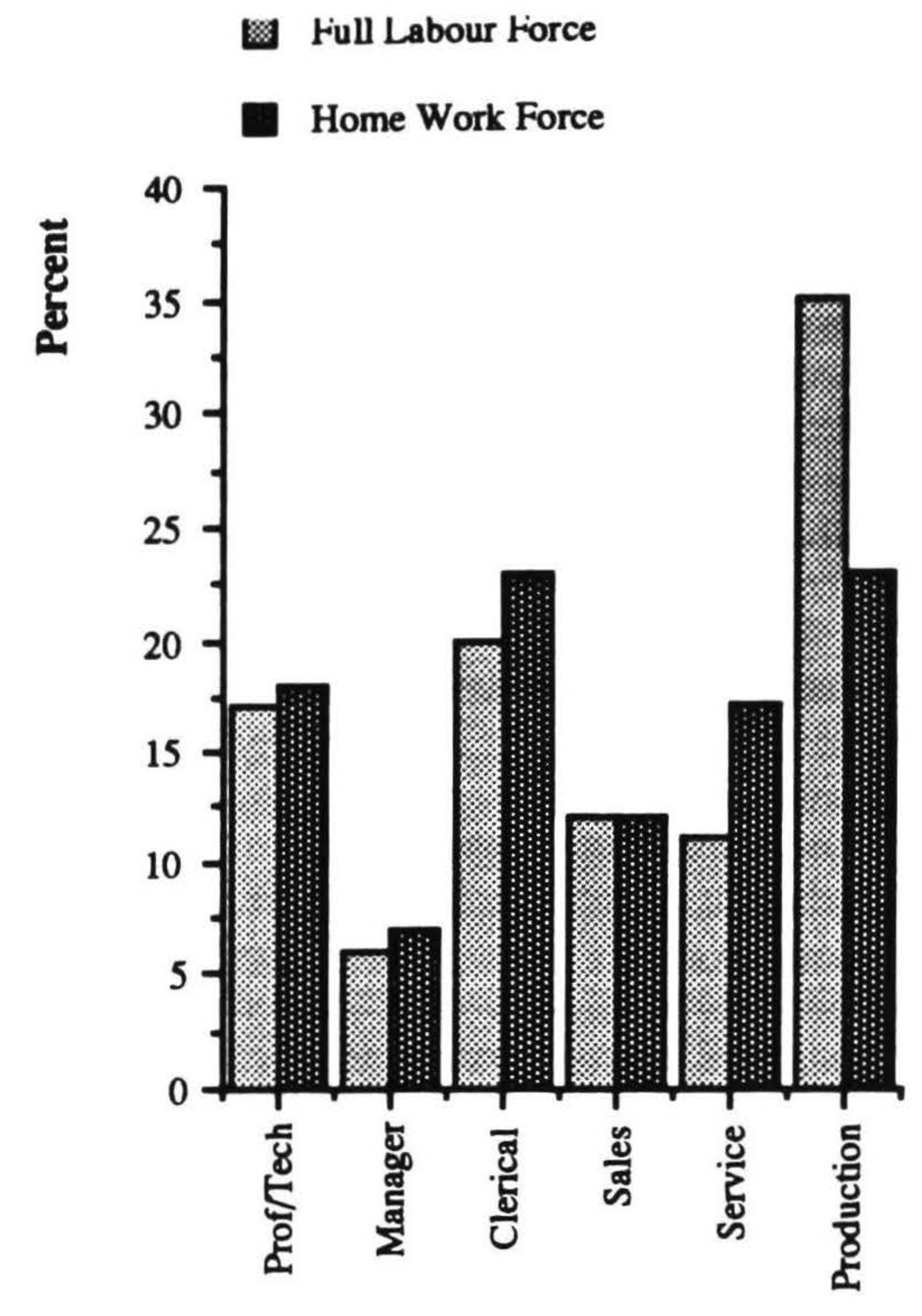

Source: Department of Statistics

work generally points out that those involved are dependent on their jobs rather than doing them as a "paid hobby" and this confirms that is the case in New Zealand. There is some variation over jobs, with clerical work most likely to be part-time, and service work full-time.

\section{Gender}

Gender is a major source of differentiation among those working at home which is reflected in several dimensions, for instance type of work, employment status, and education. Some of the differences in type of work which are typical of the whole work force are reflected among those who work at home; where the balance does alter, it reflects the availability of traditional female occupations at home. Overall, the proportion of women in the general work force is $41 \%$, with women making up $62 \%$ of those working at home.

In the full work force the proportion of all men in professional work is similar to that of women, whereas for those working at home the proportion of all women professionals is much lower than that of men and lower than in the general work force, probably because teaching and nursing are not available (see Figure Two). The proportion of women at home who were in managerial work is much higher than for the general population (but they may be in a more restricted range of jobs, possibly managing small businesses). Male clerical workers are 
Table 1 Common home work occupations

General clerk

Working proprietors, service

Manager

Artists, authors etc

Sewing

Secretary, typist

Working proprietor, sales

Book keeper

Architects, engineers

Shop assistant

Religious workers

Construction workers

Managers, services

Knitting/finishing

Fitters \& turners, mechanics

Drivers

Housework

Electrical workers

Plumbers, welders
Male SE Female SE Male OtherFemale Other

Total

$\begin{array}{rr}12 & 1101 \\ 1644 & 1650 \\ 1164 & 1155 \\ 1080 & 1701 \\ 306 & 1158 \\ 18 & 783 \\ 1245 & 1185 \\ 48 & 609 \\ 1122 & 138 \\ 171 & 507 \\ 69 & 21 \\ 723 & 42 \\ 69 & 78 \\ 48 & 282 \\ 603 & 27 \\ 375 & 78 \\ 3 & 48 \\ 498 & 45 \\ 399 & 9\end{array}$

39
144
312
117
30
18
81
30
75
123
744
129
393
9
75
114
30
57
45

3330

339

684

228

1563

2016

189

1272

33

417

195

12

318

426

18

102

603

51

45
4482

3777

3315

3126

3057

2835

2700

1959

1368

1218

1029

906

858

765

723

669

684

651

462

Source 1986 census, 1986 DSIR data from census

Figure 2. Home and Full labour Force by

\section{Occupation}

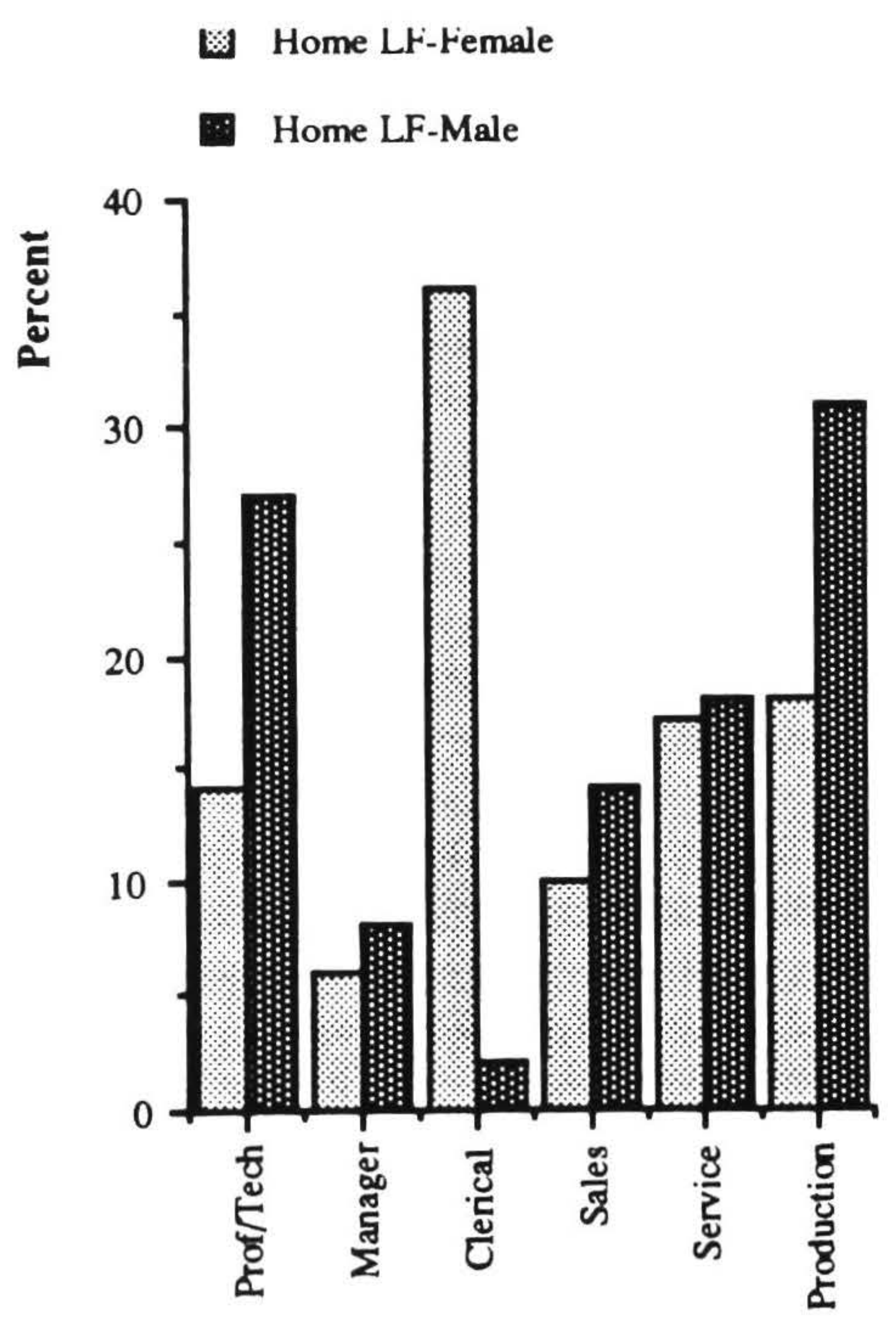

Source: Department of Statistics even less common working at home than elsewhere, but male service workers are more common. Men at home are more likely to be sales people than women, and they are also more likely to be in production, construction and transport than women, though the difference is less than in the general work force. The difference between sales workers operating from home workers and general sales workers is not as large as in most other areas.

\section{Employment status}

The proportion of self-employed also differs from that of the main population, it is more common among home workers ( $56 \%$ compared with $15 \%$ ), but most common for men (75\% are self-employed but only $45 \%$ of women). Although the levels of self-employment are very different, the distribution by occupation for home and other work is similar (see Figure Three). In the general work force those involved in production, construction and transport make up a larger proportion of the self-employed than in the home working population. Managerial and sales people are also a smaller proportion of the home working selfemployed than would be expected from looking at the general work force, while professionals and service workers are a higher proportion. Clerical work is usually done for wages rather than on a self-employed basis in the general work force, and is only slightly less likely to be done for wages or as an unpaid worker in a small family business in home work. There is also a higher proportion of professionals who are self-employed than in the general work force. 
Figure 3. Self-Employment by Occupation

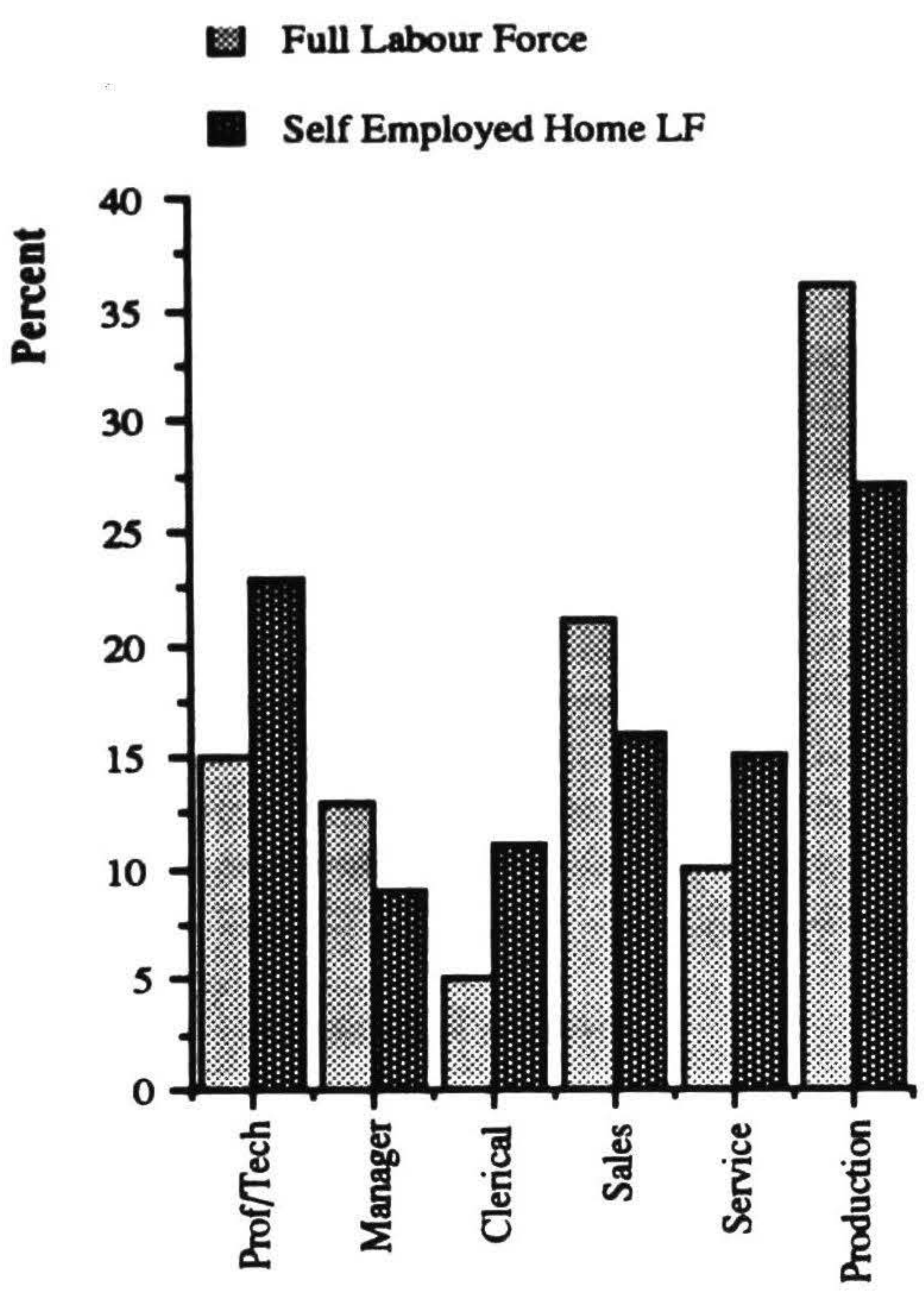

Whether involved in home work or other work, women are considerably less likely to be self-employed. However the differences between males and females across occupations were reduced for those working at home. In spite of this males were still more likely to be selfemployed in production, construction and transport, and professional work and there was an even higher proportion of self-employed women working at home in clerical work than in general.

\section{Education}

Initial investigation shows that the proportion of those in the general work force and home workers with tertiary education is nearly identical ( $42 \%$ compared with $41 \%$ ). Even when individual occupational groups are compared the differences between the home and full work force seem less than for other factors such as gender and employment status. Those in the home work force without tertiary qualifications seem slightly more likely to be in professional, managerial and service jobs, but less likely to be in production, construction and transport than would be expected from looking at the figures for the full work force.

Those with no qualifications are the majority in most occupations, regardless of gender. In the general work force men are slightly more likely to have qualifications than women (42\% compared with $35 \%$ ), but the gap widens for those at home because these men are better qualified than in general (53\% compared with $46 \%$ have tertiary qualifications). Because the female work force has so many nurses and teachers, these people hold the majority of the tertiary qualifications in the full work force, followed by clerical workers. Since there are so few women in this area working at home, clerical workers take over as the largest group with tertiary qualifications, although as individuals they are less likely to be qualified.

The most striking difference for both groups is between men and women in production, construction and transport, where about half as many women as men have tertiary qualifications. The only area where women are more likely to be qualified than men is in managerial jobs in the general work force, confirming that women managers working at home are probably in much smaller businesses than the average manager. It is interesting that although male clerical workers at home are rare, they are more likely state themselves to be in supervisory positions in the general population. Sales and service workers follow a similar pattern, with men working at home he ing beuer qualified than both women and men in general.

Self-employed people are also better educated than the work force in general (see Table Two). Because qualifications, or the need to accumulate capital and experience, restrict access to self-employment in some cases, the distribution of people in different types of work is also related to age. The general work force is much younger than those working at home. At home $69 \%$ are over 35 years as opposed to $50 \%$ in the full work force, and working at home is particularly popular for those over 65 $-15 \%$ of them work at home. As educational standards are rising, this would mean home workers could be expected to have lower qualifications than the general work force, as they are sometimes older.

Table 2. Percent with tertiary qualification

\begin{tabular}{lcccc} 
& $\begin{array}{c}\text { Self-employed } \\
\text { MaleFemale }\end{array}$ & \multicolumn{2}{c}{ Other } \\
& $\%$ & $\%$ & $\%$ & $\%$ \\
General work force & 46 & 36 & 41 & 34 \\
Home work force & 53 & 37 & 48 & 30
\end{tabular}

Source: 1986 census, 1986 DSIR data from census

\section{Income}

As would be expected from a review of the literature, incomes for home work were less than for the general work force overall. To simplify the presentation of this data I have calculated group means from data which was received from the Statistics Department in a recoded form. These means may be an inaccurate representation of the real mean, but are consistent across categories and demonstrate 
differences between groups. If income means are ranked the pattern is consistent for full-time work, but part-time work may be more remunerative for both male and female home workers (see Table Three).

Incomes vary with occupational group, by up to $\$ 8,000$ for full-time female workers, but in the same direction in both the home and general work force (in rank order, with managerial as highest, followed by professional, clerical, sales, service and production as lowest). Managerial work for full-time women was very well paid in comparison to all other jobs, but less than 1,000 fall into this group.

\section{Home work trends}

Home work has not increased as rapidly as part-time work and self-employment since 1981 . The 1991 census shows that overall numbers have dropped slightly, although we expected that the casualisation occurring within our work force would lead to an increase in home work. Until a full occupational coding which matches 1986 data becomes available the significance of this apparent stagnation will not become clear, but available data suggests that change has affected sub-groups differently. The number of women has decreased while men have increased. White collar work has also increased, while trades and services appear to have decreased. Self-employment has increased. These differences are consistent with our expectation that redundant workers would be likely to boost home work numbers. There may be no major differences in occupations at the major group level, but we would expect individual occupations to show interesting developments.

\section{Conclusion}

The results show the variety of situations faced by people working at home. Many of those included in this study are explicitly excluded from theoretically oriented studies of home work because their characteristics are similar to those of small business owners in general. The definition of industrial homework has come to be inseparable from study of people with restricted access to the labour market who are vulnerable to exploitation. This is appropriate if the focus is relations of production, but looking at the differences between home and general workers of higher status and income also tells us something about home work, as many of the differences related to gender or employment status apply to more than one job type.

All the characteristics studied, gender, employment status, education, income and occupation are closely interlinked and we cannot state that any one factor is the key to understanding the situation. Gender is clearly important, but so is employment status. Compared with clerical work, which is dominated by female wage workers, professional work, production, construction and transport are the domain of male self-employed. Some occupations within these categories are almost exclusively male. Because of our broad definition of home work we can point out that although some women are likely to be forced into
Table 3. Income means

\section{Employment category}

Grouped Mean

Full-time males in the general work force Full-time males in the home work force

Full-time females in the general w'k force Full-time females in the home work force

Part-time males in the general work force

Part-time males in the home work force

Part-time females in the general w'k force

Part-time females in the home work force

$\$ 8,880$

\section{Source: 1986 census, 1986 DSIR data from census}

home work, other women are clearly well off working at home. It will be interesting to trace change over time in individual occupations and our future work will concentrate on this activity.

\section{Future Research}

It is difficult to gauge the future as the limited 1991 census data available as yet does not establish the meaning of the trends to more white collar and male home workers. Peter Brosnan (1991) has shown how increased flexibility in the retail trade has occurred at the same time that hours have increased, and security and wages have decreased. It is likely that the situation of home work will be much more confused than this, with some benefiting from home work more than others, but it is clear that some home workers are vulnerable. As the general New Zealand work force has suffered, with the number of jobs declining and conditions tending to deteriorate, home workers are likely to have suffered also. It is likely that home work will be influenced by any global trends, for instance the decline of our clothing industry, or the increase in small service businesses, but until individual occupational data is available it is not possible to comment on this.

Analysis of the major occupational groups suggests there are considerable openings for the use of information technology. Clerical and professional jobs, structured around written information, are the most obvious areas where information technology is likely to facilitate current home work or create new opportunities. However small businesses may also benefit from links with other organisations which provide services such as clerical or accounting work, and sales people are already making use of links back to main offices for information on stores and direct ordering. In 1986 nearly one quarter of those working at or from home full-time were in white collar occupations. Although many of these people, for example music teachers, are unlikely to depend on information technology in the future, it is an obvious advantage for many and other research involving small business carried out by the New Zealand Institute of Social Research and Development shows the prevalence of computers where 
information handling is important ${ }^{5}$. Future work on the 1991 census data will focus on technological change.

It is now widely accepted that technology is a result of a social process in which the relationship between employers and their workers is a key factor. The way new equipment is designed and integrated with existing forms of work organisation is driven by many factors other than productivity, including work force control. New technology may allow new forms of work organisation and creative opportunities for workers, but it may also allow old employee-employer relationships to continue. Looking at changes in occupation among home workers will indicate whether the potential for new forms of work such as telework are expanding. Doing this in conjunction with variables such as gender, employment status, income, and education will allow us to comment on whether the occupations involved offer desirable conditions and whether home work is likely to lose its reputation for exploitative conditions as such technological change becomes more pervasive.

\section{Notes}

1 This current paper has provided an introduction to the data on home work in New Zealand available from the 1986 census. Once this database is combined with the 1991 data, further work will be possible and the New Zealand Institute of Social Research and Development (members of which were formerly employed by DSIR Social Science) is planning a report which will outline the current situation. This work is funded by the Foundation for Science, Research and Technology and will focus on technological change. However there are many other issues which could be explored with the data available.

2 It is extremely difficult to separate home based workers from those working in their homes. Sales and some service jobs could be either. Many production, construction and transport jobs are clearly home based. Up to half the males in this category may be home based, although the proportion of women is very small. Within these occupations, only a small proportion are working at home, suggesting there are other home based workers who are not included in our figures. The proportions of home-workers giving their occupation as commercial travellers or motor vehicle drivers, who are more likely to be home-based, was small and the majority in these occupations did not state themselves as working from home $(3.7 \%$ and $1.8 \%$ of all those in these occupations respectively) which suggests that the New Zealand figures largely exclude those using their home as a base only. Where numbers are small, random rounding may also obscure the true picture. A question in the census (Q29) which appears to give a more accurate picture of home work is not entered into their database by the Department of Statistics.
${ }^{3}$ Loveridge, A and Schoeffel, P. 1991. Who works at home? a New Zealand profile. DSIR Social Science: Christchurch, gives more detail on age, industrial group and region.

4 These figures are also summarised in Tables Four and Five. Figures in which the home work force differs significantly from the general work force are shown in normal type, those which do not are shown in bold type italics. Because the numbers are so large, even a small difference is statistically significant. $95 \%$ confidence intervals were calculated for the home work force and these were compared with the general work force, minus the home work force. All the graphs and tables in this paper are based on the general work force including home workers, because these are commonly used and allow comparison with other studies to be made, but this is not suitable for calculating statistical significance. Excluding home workers from the general workforce makes very little difference to most percentages (less than $1 \%$ ). The only cases where the differences are larger are for those who are over 65 years old, $15 \%$ of whom are home workers, and self-employed women, many of whom also work at home.

${ }^{5}$ Half of the 102 small businesses contacted during research into demand for a telework centre had a computer, almost as many had a fax. This is not a random sample, as the non-response rate was high, but indicates growth of computer use where paper work is high (Loveridge, A and Schoeffel, P. A report on the viability of a telework centre in Christchurch, New Zealand Institute of Social Research and Development: Christchurch, forthcoming)

\section{Further Reading}

Allen, Sheila and Wolkowitz, Carol 1987 Home working: Myths and Realities Macmillan: London

Armstrong, Nicola forthcoming Teleworking and Gender Relations

Boris, Eileen, and Daniels, Cynthia eds. 1989 Historical and Contemporary Perspectives on Paid Labor at Home University of Illinois Press: Urbana and Chicago

Brosnan, Peter 1991 'Labour Market Flexibility and theQuality of work: a Case Study of the Retail Industry' New Zealand Journal of Industrial Relations 16: 13-36

Foggo, Penny 1992 'Reconceptualising the Home Work Divide: A Case Study of Home Work' Unpublished MA thesis, Department of Geography, University of Waikato 
Haines, Lesley 1989 Work Today: Employment Trends to 1989 New Zealand Planning Council:

Wellington

Hakim, Catherine 1988 'Homeworking in Britain', In On Work: Historical, Comparative, and Theoretical Approaches ed. R E Pahl. Basil Blackwell: Oxford

Huws, Ursula et al. 1990 Telework: Towards the Elusive Office Wiley: England

Loveridge, Alison and Schoeffel, Penelope 1991. Who works at home? A New Zealand profile. Working Papers in Information Technology and Society No 2 DSIR Social Science: Christchurch

Loveridge, Alison 1992 'Occupational and Class Mobility among the Farm Workforce' Unpublished PhD thesis, Department of Sociology, University of Auckland

NACEW (National Advisory Council on the Employment of Women) 1990 Beyond the Barriers: The State, the economy and Women's Employment 1984-1990 Department of Labour: Wellington

Scase, Richard; and Goffee, Robert 1987 The Real World of the Small Business Owner Croom Helm: London

Schoeffel, Penelope, Loveridge, Alison and Davidson, Carl 1991 Telework in New Zealand: The Present Situation and Future Prospects Working Papers in Information Technology and Society No 1, DSIR Social Science: Christchurch

Willis, Evan ed. 1988 Technology and the Labour Process Allen and Unwin: Sydney 